East African Medical Journal Vol. 87 No. 2 February 2010

PROGNOSTIC FACTORS IN PATIENTS HOSPITALISED WITH DIABETIC KETOACIDOSIS AT KENYATTA NATIONAL HOSPITAL, NAIROBI

C.F. Otieno, MBChB, MMed, Senior Lecturer, J.K. Kayima, MBChB, MMed, Senior Lecturer, Department of Clinical Medicine and Therapeutics, College of Health Sciences, University of Nairobi, P.O. Box 19676-00202, Nairobi, Kenya, P.K. Mbugua, MBChB, MMed, Division of Medicine, Kenyatta National Hospital, P. O. Box 20723, Nairobi, Kenya, A.A. Amayo, MBChB, MMed, Senior Lecturer, Department of Clinical Chemistry and S.O. McLigeyo, MBChB, MMed, Associate Professor, Department of Clinical Medicine and Therapeutics, College of Health Sciences, University of Nairobi, P.O.Box 19676-00202, Nairobi, Kenya

Request for reprints to: Dr. C.F. Otieno, Department of Clinical Medicine and Therapeutics, College of Health Sciences, University of Nairobi, P.O. Box 19676-00202, Nairobi, Kenya

\title{
PROGNOSTIC FACTORS IN PATIENTS HOSPITALISED WITH DIABETIC KETOACIDOSIS AT KENYATTA NATIONAL HOSPITAL, NAIROBI
}

\author{
C. F. OTIENO, J. K. KAYIMA, P. K. MBUGUA, A. A. AMAYO and S. O. MCLIGEYO
}

\begin{abstract}
Background: In spite of many advances in the management of diabetes in the last 25 years, the mortality associated with diabetic ketoacidosis (DKA) remains high, especially in the developing countries. The mortality appears greatest in the first $24-48$ hours of their treatment. Most of the previous studies on DKA focused on children and the precipitating factors thereof but not particularly on clinical predictors of outcomes. Objective: To determine the clinico-laboratory predictors of outcomes of patients hospitalised with diabetic ketoacidosis who were undergoing treatment.

Design: Cross-sectional descriptive study.

Setting: The accident and emergency department and medical wards of the Kenyatta National Hospital.

Subjects: Fifty one patients hospitalised with diabetic ketoacidosis over a nine month period were evaluated clinically and by laboratory tests. They were managed in the standard way with insulin, intravenous fluids and appropriate supportive care.

Main outcome measures: Serial assays of serum electrolytes, glucose and blood $\mathrm{pH}$, HbA1c and clinical outcome of either discharge home or death.

Results: Of the 51 patients enrolled, 47 were included in the final analysis. Fourteen (29.8\%) patients died, and the deaths occurred within less than 48 hours of hospitalisation and treatment. Of the patients who died, all $(100 \%)$ had altered level of consciousness at hospitalisation, $71.4 \%$ had abnormal renal functions, $64.3 \%$ were newly diagnosed and an equal proportion of $64.3 \%$ were females. The alteration in the level of consciousness was significantly associated systolic hypotension and severe metabolic acidosis, $(\mathrm{p}<0.001)$. Patients with altered level of consciousness also had poorer renal function.

Conclusion: Apparently DKA still carries high mortality during treatment in hospital. Altered level of consciousness, which is an obvious and easily discernible clinical sign, was a major predictor of mortality in our study patients. The majority of patients with altered level of consciousness also had systolic hypotension, severe metabolic acidosis and impaired renal function. Even where and when detailed laboratory evaluation is elusive, clinical signs, especially altered level of consciousness and systolic hypotension are very important markers of severity of DKA that may be associated with unfavourable outcomes. Further studies are necessary to establish why DKA still carries high mortality in the patients who are already receiving treatment in hospitals in developing countries.
\end{abstract}

\section{INTRODUCTION}

Despite advances in diabetes management over the past 25 years, the incidence of mortality associated with diabetes ketoacidosis (DKA) remains unchanged (1). The mortality appears to be greatest among patients at first presentation (2), if there has been a long history of symptoms before hospitalisation (3) and during the first 24 hours of treatment (4). Most of these studies have been on children.

In developing countries, mortality from diabetes ketoacidosis has been unfavourably high. McLarty 
et al (5) found that patients requiring insulin prehospitalisation had particularly worse hospital survival than those that did not require insulin, amongst the former 26\% died of DKA. Ahmed et al (6) found that DKA was responsible for $54 \%$ of diabetic hospitalisations in a Sudanese hospital over a two year period. This Sudanese study did not specify important clinico-laboratory predictors of outcomes.

We picked in this study, some easily measurable clinico-laboratory parameters and evaluated their relationship with the outcome of our patients who were hospitalised with diabetic ketoacidosis.

\section{MATERIALS AND METHODS}

This was a prospective descriptive study carried out at theKenyatta National Referral and Teaching Hospital from December 2001 to August 2002. The study was approved by the institutional review board. The main objective was to evaluate clinical and laboratory characteristic and outcome of diabetic patients who were hospitalised in diabetes ketoacidosis state within the study period. The main outcomes were either death or successful discharge from the hospital. Apparently, most of the patients succumbed within the first 30-48 hours of hospitalisation. Diabetes ketoacidosis was defined as hyperglycaemia above $14.0 \mathrm{mmol} / \mathrm{l}$, an arterial blood $\mathrm{pH}$ less than 7.3 , serum bicarbonate less than $15 \mathrm{mmol} / 1$ with moderate to marked ketonuria, qualitatively assessed asketonuria $(2+$ to $3+)(7)$. Patients were consecutively recruited and enrolled into the study if on satisfying the study definitions and consent obtained either from self or guardian. This was a clinical study of usual care and there were no other unusual study requirements. There was a likely benefit of closer supervision of treatment and frequent laboratory monitoring.

Within the study period of nine months, 648 patients with diabetes were hospitalised through the accident and emergency unit to the various wards - medical, surgical or intensive care units of the hospital. The clinical state of the patient determined which ward was appropriate for stay of the study patient, with assistance of one of the authors (PKM). Fifty one $(51 / 648)$, about $8 \%$ of the patients met the inclusion criteria, consent was obtained and were consequently enrolled into the study. The patients presented to the hospital at any time of the 24 hour day, and the initial evaluation was done at the accident and emergency department.

For each patient, a medical history was taken, where possible, to include time of onset and duration of symptoms, the age, diabetes history and mode of glycaemic control. Physical examination was extensively performed; vital signs of temperature, respiratory rate, pulse and blood pressure on the arm from a lying position were determined and recorded. Important parameters in the physical examination were level of hydration, identification of acidotic (Kussmaul) breathing (8), and level of consciousness based on Glasgow Coma Scale (GCS) (9). During the systemic physical examination, clinical evidence of any other disease process like meningitis, chest infection, etc, were looked for.

The first elaborate laboratory assays were taken at the initial evaluation, within or less than two hours of presenting to hospital. The time lapse was related to registration procedures of a patient going on the ward. However, any patient who required any resuscitation was addressed appropriately without undue delay. The first laboratory assays were random blood glucose (by hand glucometer) and dipstick ketonuria for diagnosis. Other laboratory tests were: total blood gas and $\mathrm{pH}$ analysis, serum magnesium, phosphates, liver function profile and blood cultures where indicated. These tests were taken on the first intravenous canulation before intravenous fluids were commenced. The next blood samples were taken within six hours of a patient's hospitalisation or from the time initial samples were taken; 24 hours and then daily for arterial blood $\mathrm{pH}$ and gases and renal functions (especially creatinine and electrolytes$\mathrm{Na}$ and $\mathrm{K}$ ). Blood glucose levels were determined two hourly until the DKA state was fully reversed clinically. Any other necessary blood tests that were done within less than six hours of hospitalisation were not used in the data analysis.

The treatment that was given to each study patient consisted of solubleinsulin, intravenous fluids of either normal saline or dextrose or Hartmanns solutions and any other necessary requirement as appropriate for the individual patient.

Other investigations were done on patients as indicated/necessary including plane chest radiograph; urinalysis including microscopy and culture/sensitivity; and electrocardiogram.

Specific laboratory methods were: randomblood glucose was doneby "Surestep" glucometer (Lifescan, Johnson \& Johnson, USA), which detects maximum blood glucose of $27.8 \mathrm{mmol} / 1$, also gives blood glucose results $10-15 \%$ less than plasma glucose.

Arterial blood was obtained from brachial or radial artery for $\mathrm{pH}$ gas analysis on an automated machine (rapid Lab348, Bayer Diagnostics, Colchester Rd, Halstead, England). Urine was obtained as mid-stream specimen in the conscious or by aseptic catheterisation in the comatose patients on which culture and sensitivity was done in appropriate media.

Total blood count was done on $2 \mathrm{ml}$ EDTA blood in automated machine (Cell Dyn 1300 Abbot Laboratories, USA). Urea and electrolytes $\left(\mathrm{Na}^{+}, \mathrm{K}^{+}, \mathrm{Cl}\right.$ including $\mathrm{Mg}^{+}$, phosphates) in $3 \mathrm{ml}$ serum specimen 
were done in automated machine (Technicon R.A. 1000 analyzer), using IMx analyzer machine (Abbot Laboratories, USA).

Data analysis and statistical methods: SPSS 10 package was used. Data were summarised in proportions for categorical ones, and into means (S.E.) or SD for the continuous variables. Specific continuous variables like blood $\mathrm{pH}$ and serum creatinine were categorised as either normal or abnormal and the patients in either category reported as proportions. Comparison of means (S.D) were done using student t-tests, associations were tested using Fisher's Chisquare test.

\section{RESULTS}

Fifty one of 648 patients hospitalised with diabetes within a nine-month period had diabetic ketoacidosis, and were enrolled into the study. Out of the 51 patients, one died before the full investigations were done, another three were excluded for incomplete data. Finally 47 study participants were analysed and $46.8 \%$ were female.

Table 1

Socio-demographic profile of patients with diabetic ketoacidosis in the study

\begin{tabular}{|c|c|c|c|}
\hline Characteristic & $\begin{array}{l}\text { Total population } \\
\text { No. }(\%)\end{array}$ & $\begin{array}{l}\text { Males } \\
\text { No. }(\%)\end{array}$ & $\begin{array}{l}\text { Females } \\
\text { No. }(\%)\end{array}$ \\
\hline Number $(\%)$ & 100 & $25 \quad 53.2$ & 2246.8 \\
\hline Mean age (years) $\pm(S D)$ & $33.42 \pm 15.21$ & $37 \pm 18.12$ & $29.86 \pm 14.3$ \\
\hline Newly diagnosed diabetics & 51.1 & $14 \quad 58.3$ & $10 \quad 41.7$ \\
\hline Previously known diabetics & 48.9 & 1147.8 & $12 \quad 52.2$ \\
\hline Mean duration of diabetes (years) & $4.64 \pm 5.62$ & $5.0 \pm 4.42$ & $3.40 \pm 3.70$ \\
\hline Patients with $\mathrm{HbAIc} \leq 7.0 \%$ & $1 \quad 2.1$ & 0.5 & $0 \quad 0$ \\
\hline$(>7-8 \%)$ & 4.3 & 50 & 50 \\
\hline$(>80 \%)$ & $44 \quad 93.6$ & $20 \quad 45.5$ & $24 \quad 54.5$ \\
\hline
\end{tabular}

Figure 1

Age and gender distribution of the study patients



Age categories (years) 
Figure 2

Prevalence of selected symptoms of study patients at initial presentation to hospital

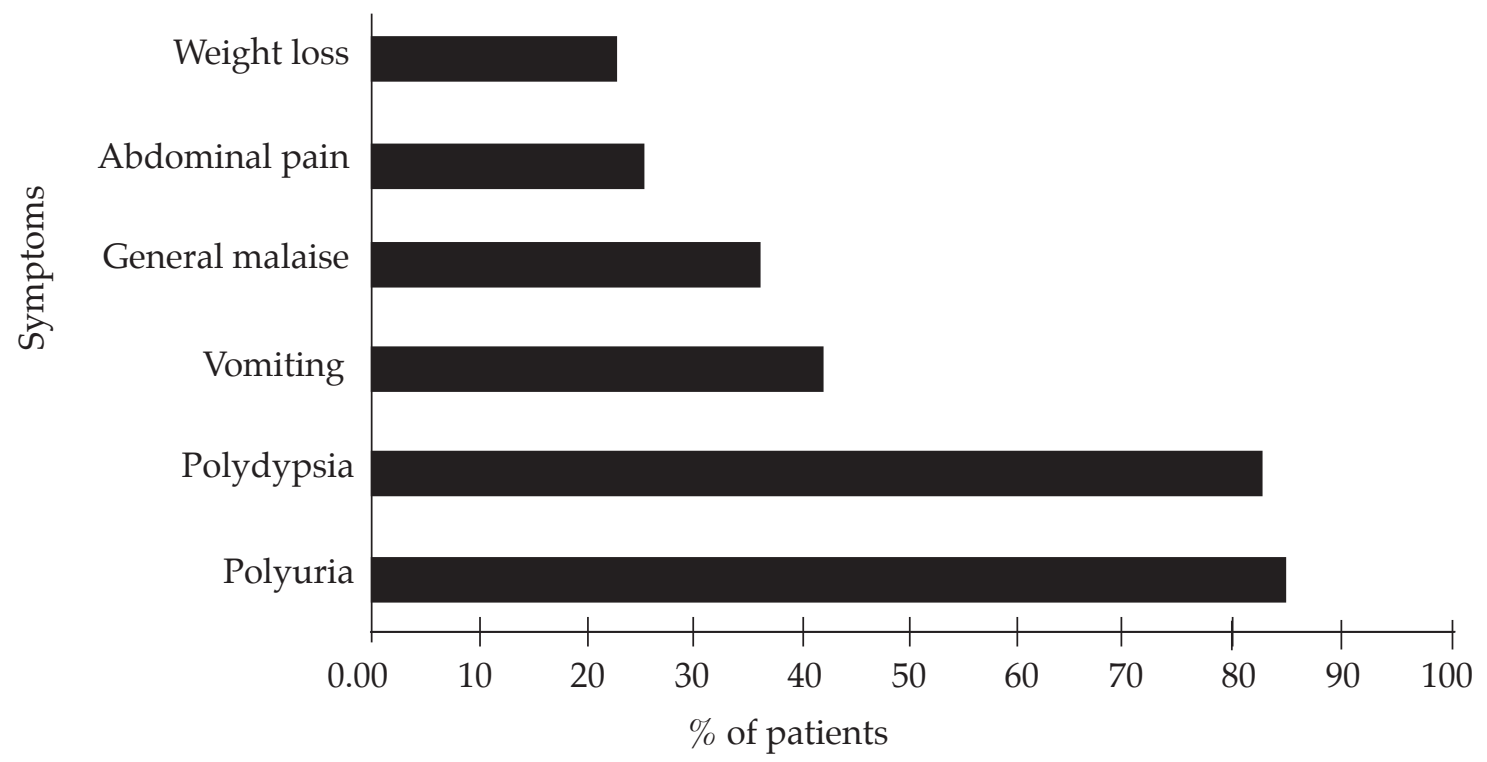

Figure 2 above emphasizes the two major symptoms were responsible for enhancing water loss on the of polyuria $(85.1 \%)$ and vomiting $(42.5 \%)$ that background of inadequate oral intake.

\section{Table 2}

Clinical signs of the study patients at initial hospitalisation

\begin{tabular}{lcl}
\hline \multirow{2}{*}{ Level of consciousness } & Proportion of patients \\
& No. $(\%)$ \\
\hline GCS 13-15 - fully conscious & 19 & 40.4 \\
GCS 9-12 - drowsy & 11 & 23.4 \\
GCS 3-8 - obtunded to coma & 17 & 36.2 \\
Hydration status & & \\
Mild dehydration & 12 & 25.5 \\
Moderate dehydration & 20 & 42.6 \\
Severe dehydration & 15 & 31.9 \\
Vital signs & & \\
Tachycardia $(>100$ beat per minute) & 14 & 29.8 \\
Hypotension $(\mathrm{SBP}<100 \mathrm{mHg})$ & 17 & 36.2 \\
Hypothermia $\left(\mathrm{T}<35^{\circ}\right)$ & 18 & 37 \\
Acidotic (Kussmaul) breathing & 36 & 76.6 \\
\hline
\end{tabular}


Table 3

Characteristics and laboratory parameters of the study patients by their first renal function status at hospitalisation

\begin{tabular}{|c|c|c|}
\hline \multirow{3}{*}{ Parameter } & \multicolumn{2}{|c|}{ First serum creatinine level at hospitalisation } \\
\hline & Normal serum & Abnormal serum \\
\hline & Creatinine $\leq 120 \mu \mathrm{mol} / 1$ & Creatinine $>120 \mu \mathrm{mol} / 1$ \\
\hline Proportions & $\mathrm{n}=18$ & $\mathrm{n}=29$ \\
\hline No. of patients who died & $5 / 18(27.8)$ & $9 / 29 \quad(31.0)$ \\
\hline Age (years) $($ mean $\pm \mathrm{SD})$ & $30.28(16.82)$ & $35.76 \quad(16.50)$ \\
\hline HbAlc $(\%)($ mean \pm SD $)$ & $13.32(1.84)$ & $12.40 \quad(2.08)$ \\
\hline Duration of diabetes (years) (mean \pm SD) & $0.92 \quad(1.26)$ & $3.11 \quad(5.6)$ \\
\hline $\mathrm{pH}$ at 6 hours of hospitalisation $($ mean $\pm \mathrm{SD})$ & $7.25 \quad(0.17)$ & $(0.12)$ \\
\hline $\mathrm{pH}$ at 24 hours of hospitalisation (mean \pm SD) & $7.32 \quad(0.13)$ & $(0.03)$ \\
\hline Random blood glucose at hospitalisation & & \\
\hline$(\mathrm{mmol} / \mathrm{l})($ mean $\pm \mathrm{SD})$ & $26.9 \quad(2.4)$ & $(2.6)$ \\
\hline Potassium $\left(\mathrm{K}^{+}\right)$at hospitalisation $(\mathrm{mmol} / \mathrm{l})$ (mean $\pm \mathrm{SD}$ & $5.80 \quad(1.4)$ & $(1.6)$ \\
\hline Potassium $\left(\mathrm{K}^{+}\right)(\mathrm{mmol} / \mathrm{l})($ mean $\pm \mathrm{SD})$ at 24 hours & $(0.6)$ & $(0.9)$ \\
\hline Systolic BP at hospitalisation $(\mathrm{mmHg})($ mean $\pm \mathrm{SD})$ & $105.6(13.8)$ & $113.1 \quad(17.3)$ \\
\hline Diastolic BP at hospitalisation $(\mathrm{mmHg})($ mean $\pm \mathrm{SD})$ & $61.7 \quad(11.5)$ & $(11.4)$ \\
\hline $\mathrm{BUN} \mathrm{mmol} / \mathrm{l}(\mathrm{mean} \pm \mathrm{SD})$ & $(5.1)$ & $(9.8)^{* *}$ \\
\hline
\end{tabular}

${ }^{* *} \mathrm{P}<0.01$, significant difference

$\mathrm{BP}=$ Blood Pressure

BUN=Blood Urea Nitrogen

Table 4

Characteristics and laboratory parameters of the study patients by their level of consciousness at hospitalisation

\begin{tabular}{|c|c|c|c|}
\hline & $\begin{array}{l}\text { Norm } \\
\text { consci }\end{array}$ & $\begin{array}{l}\text { al level of } \\
\text { ousness }\end{array}$ & $\begin{array}{l}\text { Abnormal level of } \\
\text { consciousness }\end{array}$ \\
\hline Proportion of patients & $19 / 47$ & & $28 / 47$ \\
\hline Proportion of patients who died & $0 / 19$ & & $14 / 28^{* *}$ \\
\hline Age (years) $($ mean $\pm S D)$ & 33.4 & $(19.0)$ & $33.7 \quad(16.3)$ \\
\hline $\operatorname{HbAlc}(\%)($ mean $\pm \mathrm{SD})$ & 13.12 & $(1.11)$ & $12.6 \quad(2.17)$ \\
\hline $\mathrm{pH}$ at 6 hours of hospitalisation (mean \pm SD) & 7.31 & $(0.08)$ & $7.24 \quad(0.15)$ \\
\hline $\mathrm{pH}$ at 24 hours of hospitalisation (mean \pm SD) & 7.36 & $(0.06)$ & $7.32 \quad(0.01)$ \\
\hline First random blood glucose $(\mathrm{mmol} / \mathrm{l})($ mean $\pm \mathrm{SD})$ & 26.9 & $(2.6)$ & $26.9 \quad(2.5)$ \\
\hline First potassium $\left(\mathrm{K}^{+}\right)$at hospitalisation $($mean $\pm \mathrm{SD})$ & 4.2 & $(0.7)$ & $(0.45)$ \\
\hline Potassium $\left(\mathrm{K}^{+}\right)$at 24 hours hospitalisation (mean $\pm \mathrm{SD}$ ) & 4.0 & $(0.34)$ & $4.10 \quad(0.9)$ \\
\hline Systolic BP $(\mathrm{mmHg})$ at hospitalisation (mean $\pm \mathrm{SD})$ & 113.3 & $(14.1)$ & $109.5(16.9)^{+}$ \\
\hline Diastolic BP $(\mathrm{mmHg})$ at hospitalisation(mean $\pm \mathrm{SD})$ & 64.4 & $(5.3)$ & $63.8 \quad(12.6)$ \\
\hline Duration of diabetes (years) (mean \pm SD) & 0.81 & $(1.30)$ & $2.62 \quad(4.96)$ \\
\hline BUN mmol/l (mean \pm SD) & 7.26 & $(4.42)$ & $13.4(9.76)^{*}$ \\
\hline
\end{tabular}

** Chi-square, $\mathrm{p}<0.01$, abnormal level of consciousness was significantly associated with death

* Student t-test, $\mathrm{p}<0.05$, patients with abnormal level of consciousness had poorer renal function

+ Systolic hypotension was significantly $(\mathrm{p}=0.009)$ associated with severe acidosis 
Table 5

Summary of clinical characteristics/events of the study patients who died

\begin{tabular}{lc}
\hline Clinical/laboratory characteristic & $\begin{array}{c}\text { Proportion of patients with } \\
\text { the characteristic who died }(\%)\end{array}$ \\
\hline Abnormal renal function & 71.4 \\
Altered level of consciousness & 100 \\
Newly diagnosed patients with diabetes & 64.3 \\
Females & 64.3 \\
\hline
\end{tabular}

Fourteen of $47(29.8 \%)$ of the patients who died were analysed, $71.4 \%$ had abnormal renal function profiles, all $(100 \%)$ had altered level of consciousness, 9/14 $(64.3 \%)$ were newly diagnosed and 9/14 (64.3\%) were females.

Renal dysfunction at hospitalisation (first serum creatinine level $>120 \mu \mathrm{mol} / \mathrm{l}$ ) was significantly associated with altered level of consciousness $(\mathrm{p}=0.010)$, however, altered level of consciousness per se was more significantly $(\mathrm{p}=0.028)$ associated with death than renal dysfunction.

\section{DISCUSSION}

Table 1 and Figure 1 show the characteristics of the study participants. Twenty four $(51.06 \%)$ patients were $\leq 30$ years of age, who were likely to have type 1 diabetes. The other category of study subjects above 30 years, probably a mixture of type 1 and 2 but more of type 2 diabetes, had more men. There was possibility that the more male numbers found could be a chance finding due to bias from patient preference in accessing the hospital facility or it may have been a real observation.

Other authors, (10-12) have shown a 2-3 fold higher prevalence of ketosis-prone type 2 diabetes in men. These studies did not compare mortality between men and women.

Diabetic ketoacidosis (DKA) appears to be a major cause of mortality in diabetic patients who are hospitalised. This study recorded a mortality of $29.8 \%$. The glycaemic level was very high thus betraying the underlying insulin deficiency at hospitalisation. McLarty et al (5) found that patients that required insulin had particularly worse hospital survival $(26 \%$ died of DKA) than those that did not require insulin. Ahmed et al (6) also found lack of insulin as the main precipitant of DKA.

Often when death occurs in DKA, it is listed as a clinical entity, occasionally additional complications may be included like cerebral or pulmonary oedema but scarcely are these accompanying clinical events / processes like renal dysfunction, cerebral oedema and / or hypotension mentioned on death certificates (13).
In this study, the first assay of renal profile at hospitalisation, categorised as abnormally raised serum creatinine $(>120 \mathrm{mmol} / \mathrm{l})$ was detected in about $62 \%$ of the study patients, (Table 3 ). Over $70 \%$ of patients who died had abnormal renal function (Table 5). Some published reports $(14,15)$ have described non-diabetic glomerular disease occurring in patients with diabetes mellitus, particularly with early onset proteinuria. Our study did not look for proteinuria. Moreover, in DKA, other potential risk factors / causes of renal dysfunction may occur, and these include diabetes itself, dehydration, infection and undetermined glomerular disease. More than $70 \%$ of our study patients had moderate to severe dehydration, (Table 2), with symptoms of vomiting, polyuria and hyperventilation (Figure 2), all these possibly caused and/or worsened the state of dehydration, especially on a backdrop of inadequate oral intake. Harrington et al (15) reported renal failure as an initial manifestation of diabetes, however, their patients did nothaveDKA. Pre-renal causes of kidney dysfunction may play a major role in diabetic patients in ketotic state such as our subjects were in.

All patients in our study who died had altered level of consciousness and poorer renal functions compared to those ones without alteration in the level of consciousness, (Table 4). This means that alteration in the level of consciousness was a more frequent association with mortality followed by renal dysfunction. The altered level of consciousness in this study was noted to be a sign of severe acidosis (low $\mathrm{pH}$ ). The study patients whose serum $\mathrm{pH}$ values were low were also observed to have systolic hypotension.

Altered level of consciousness may be due to metabolic derangements inherent in (characteristic of) DKA as well as therapeutic interventions especially of fluid therapy. That many of our patients presented with altered level of consciousness before therapy was initiated vindicate the probable role of abnormal energy metabolism and metabolic derangements in diabetic ketoacidosis that results in abnormal biochemistry which also affects central neurological function (2). The idea that the treatment of DKA itself might be the cause of cerebral oedema has gained 
support over the years, but no single aspect of therapy has been implicated in studies to date, furthermore cerebral eodema has been shown to be present even before treatment begins $(17,18)$.

Most $(>80 \%)$ of all our study patients had clouding of consciousness but other studies (19-21) have reported a modest (less than 20\%) proportion presenting with altered level of consciousness. The disparity in proportions of patients with altered level of consciousness in the different studies may be a reflection of time taken before the patients presented to hospital from onset of diabetic ketoacidosis, and probably the severity of disease at hospitalisation.

It is therefore evident that dehydration, hypotension, altered level of consciousness and renal dysfunction were major risk factors of unfavourable outcome (mortality) in DKA in our study patients. These have major implications on management of DKA, especially fluid and insulin therapies that are very central to reversing the effects of diabetic ketoacidosis.

Acute dehydration with a relatively larger sodium loss will result primarily in intravascular dehydration, but a more prolonged process will result in greater degree of intracellular dehydration, with relative maintenance of intravascular volume, particularly if the patient remains polydypsic (22).

In this study, the newly diagnosed patients also had very high $\mathrm{HbAlc}$ values that reflected several weeks of hyperglycaemia, or presumably long period of evolution of the DKA state. There are therefore wide variations in fluid deficits, and acid-base and electrolyte imbalances, during both development and treatment of diabetic ketoacidosis (23), yet only few of these differences in diabeticketoacidosis have been well documented (24). In deed this protean clinical picture may receive several interpretations from clinicians, which consequently would translate into varied therapeutic emphasis in the course of treating DKA.

Of particularconcern is theevidencethat clinicians tend to overestimate the degree of dehydration in diabetic ketoacidosis $(25,26)$. It is accepted that safe therapy of hypertonic dehydration requires both prolonged and cautious approach to fluid replacement to avoid the development of fits and cerebral oedema during the rehydration therapy (27).

Halting the metabolic decompensation process in DKA using insulin is the initial therapeutic goal. The other goal is provision of sufficient fluid to restore renal and hormonal homeostasis over a period of time that may be comparable to that taken for the problem to develop. In our study, it was evident that treatment had the effect of lowering potassium, this was observed in the first 24 hours, (Table3). Most guidelines are clear on how potassium replacement should be effected in DKA to avoid any catastrophes.
The differences in the biochemical and clinical pictures of patients with DKA occasioned by variations in the duration from onset, degrees of insulin deficiency and precipitating factors attests to the magnitude of challenges in their successful management. It is no wonder that when these challenges in resource-poor settingsare inadequately met, mortality remains high. From this study, patients coming to hospital in diabetic ketoacidosis who were likely to die were (had); the newly diagnosed, female gender, younger age of less than thirty, presence of renal dysfunction and, most significantly, altered level of consciousness.

\section{ACKNOWLEDGEMENTS}

To the Ethics Review Committee of Kenyatta National Hospital for approving the study and the clinical and laboratory staff of the clinical chemistry laboratory for the invaluable role they played in this study.

\section{REFERENCES}

1. Edge J.A., Ford-Adam M.E. and Dunger D.B. Causes of death in children with insulin dependent diabetes. 1990-96. Arch. Dis. Child. 1999; 81: 318-323.

2. EdgeJ.A.,Hawkins M.M., Winter D.L.etal. Incidence, presentation, management and outcome of cerebral oedema associated with diabetic ketoacidosis (DKA) in Great Britain. Arch. Dis. Child. 1999; 80 (suppl 1): A11-A15.

3. Bello F.A. and Sotos J.F. Cerebral oedema in diabetic ketoacidosis in children. Lancet. 1990; 336: 64 [Medicine].

4. Rosenbloom, A.L. Intracerebral crises during treatment of diabetic ketoacidosis. Diabetes Care. 1990; 13: 22-33.

5. McLarty, D.G. Kinabo, L. and Swai, A.B.M. Diabetes in Tanzania. II: Course and prognosis. Brit. Med. J. 1990; 13: 22-33.

6. Ahmed, A.M., Kheir, M.M. and Ahmed, N.H. Precipitating factors of diabetic ketoacidosis in adult Sudanese patients. Diabetes Intern. 2000; 3: 86-87.

7. American Diabetes Association. Hyperglycaemic crisis in patients with diabetes mellitus (position statement). Diabetes Care. 2001; 24: 154-161.

8. Lubitz, D. and Seidel J. Fluid and electrolyte therapy. In: Judith E. Tintinalli, Ronaly L. Krome, Ernest Ruiz, Editors. Emergency Medicine: A comprehensive study guide. $3^{\text {rd }}$ edition, 1992; pp 162-166.

9. Judith E. Tintinalli, Ronaly L. K. and Ernest R. Editors. Emergency Medicine;AComprehensive study guide. $3^{\text {rd }}$ edition, 1992; pp 917.

10. Mauvais-Javis, F., Sobngwi, E., Porcher, R., et al. Ketosis-prone type 2 in patients of sub-Saharan African origin: clinical pathophysiology and natural history of beta cell dysfunction and insulin resistance. Diabetes. 2004; 53:645-653.

11. Maldonado, M.R., Otiniano, M.E., Lee, R., et al. Characteristics of ketosis-pronediabetesinamulti-ethnic indigent community. Ethn. Dis. 2004; 14: 243-249. 
12. Umpierrez, G.E., Kelly, J.P., Navarette, J.E., et al. Hyperglycemic in urban blacks. Arch. Intern. Med. 1997; 157: 669-675.

13. Kasinath, B.S., Mujais, S.K., Spargo, B.H. and Katz Al. Non-diabetic renal disease in patients with diabetes mellitus. Am. J. Med. 1983; 75:318.

14. Olsen, S. and Mogensen, C.E. How often is NIDDM complicated with non-diabetic renal disease? An analysis of renal biopsies and literature. Diabetologia. 1996; 39: 1638-1645.

15. Harrington, A.R., Garella, S., Stillmant, M.M. and Chazzan, J.A. Renal failure as the initial manifestation of diabetes mellitus. Arch. Intern. Med. 1973; 132: 249-251.

16. Durr, J.A., Hoffmann, W.H., Sklar, A.H., et al. Correlates of brain oedema in uncontrolled InsulinDependent Diabetes Mellitus. Diabetes. 1992; 41: 627-632.

17. Fein, I.A., Racklow, E.C., Spring, C.L., et al. Relation of colloid pressure to arterial hypoxaemia and cerebral oedema during crystalloid volumeloading of patients with diabetes ketoacidosis. Ann. Intern. Med. 1982; 96: 570-575.

18. Ennis, E.D., Stahl, E.J. and Kreisberg, R.A. The hyperosmolar hyperglycaemic syndrome. Diabetes Rev. 1994; 2: 115-126.

19. Caroll, P. and Matz, R. Uncontrolled diabetes mellitus in adults: experience in treating diabetic ketoacidosis and hyperosmolar non-ketotic coma with low-dose insulin and a uniform treatment regimen. Diabetes Care. 1983; 6: 579-585.

20. Umpierrez, G.E., Kelly, J.P., Navairete, J.E. et al. Hyperglycaemic crises in urban blacks. Arch. Intern. Med. 1997; 157: 669-675.

21. Adrogue, H.J., Wilson, H., Boyd, A.E., et al. Plasma acid-base patterns in diabetic ketoacidosis. N. Engl. J. Med. 1982; 307: 1603-1610.

22. Kitabchi, A.E., Umpierrez, G.E., Murphy, M.I.S., et al. Management of hyperglycaemic crises in patients with diabetes. Diabetes Care. 2001; 24: 131-153.

23. Singh, R.K., Perros, P., and Frier, B.M. Hospital management of diabetic ketoacidosis: are clinical guidelines implemented effectively? Diabet. Med. 1997; 14: 482-486 [Medicine].

24. Grove, L.M., Nobel-Jamieson, C.M., Barnes, N.D., et al. Assessment of dehydration, fluid balance and insulin requirements in diabetic ketoacidosis. Proc. Br. Paediatr. Assoc. Annu. Meet. 1995; 67: 26.

25. Holliday, M.A. The evolution of therapy for dehydration: should deficit therapy still be taught? Pediatrics. 1996; 98: 171-177.

26. Harris, G.D., Fiordalisi, I., Harris, W.L., et al. Minimizing the risk of brain herniation during treatment of diabetic ketoacidemia: a retrospective and prospective study. J. Pediatr. 1990; 117: 22-31 [Medicine]. 